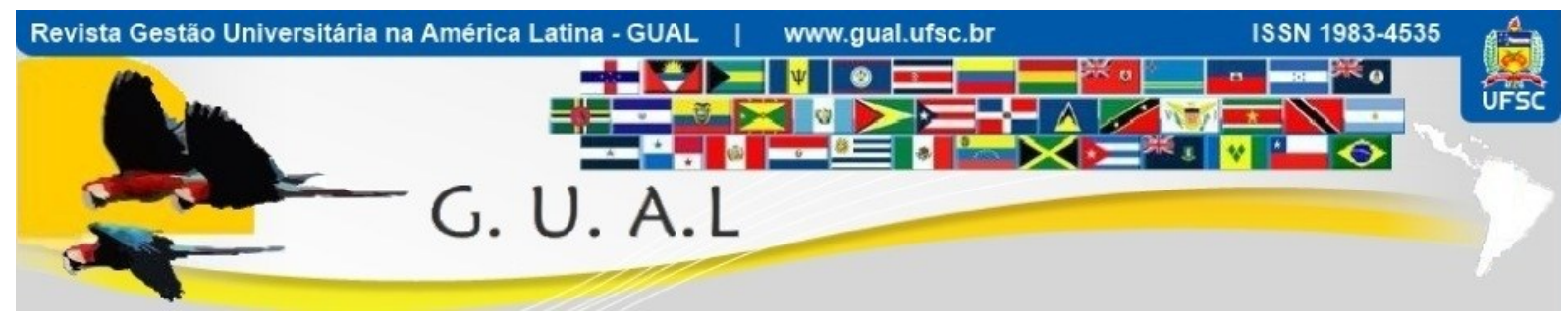

DOI: http://dx.doi.org/10.5007/1983-4535.2012v5n2p111

\title{
COMPETÊNCIAS EMPREENDEDORAS EM INSTITUIÇÕES DE ENSINO SUPERIOR: ESTUDO DE CASO
}

\section{ENTREPRENEURIAL SKILLS HIGHER EDUCATION INSTITUTIONS: A CASE STUDY}

Ana Lucia Ferraresi Schmitz, Doutora Universidade Federal de Santa Catarina - UFSC alf@ecs.ufsc.br

Edis Mafra Lapolli, Doutora Universidade Federal de Santa Catarina - UFSC edismafra@gmail.com

Recebido em 15/maio/2012

Aprovado em 25/julho/2012

Sistema de Avaliação: Double Blind Review

Esta obra está sob uma Licença Creative Commons Atribuição-Uso. 


\title{
RESUMO
}

Esta pesquisa teve como foco identificar as competências empreendedoras na Universidade Técnica de Lisboa (UTL), que possui uma estrutura organizacional compartimentada em faculdades e institutos, caracterizando-se como uma organização burocrática e hierarquizada onde o empreendedorismo torna-se um desafio para seus membros docentes, investigadores e gestores. Para o caminho metodológico desta investigação adotou-se o estudo fenomenológico e da pesquisa de campo, com abordagem qualitativa, em que a discussão do assunto e a forma do desenvolvimento são novas e originais, contando com revisão sistemática orientada pelo Cochrane Handbook, realizada no Portal da Capes. Na pesquisa de campo, adotou-se o método de entrevistas presenciais semiestruturadas com foco em comportamento. Consideraram-se, as informações obtidas pelos entrevistados e as descrições com os detalhes do comportamento. Essas informações permitiram o conhecimento das competências empreendedoras exercidas para alavancar o Instituto Superior de Economia e Gestão (ISEG), que tem se mantido como um dos diferenciais da UTL e para a própria sociedade portuguesa.

Palavras-chave: Competências empreendedoras. Empreendedorismo. Instituição de Ensino Superior.

\begin{abstract}
This research focused on identifying the entrepreneurial skills at the Technical University of Lisbon (UTL), which has an organizational structure compartmentalized in colleges and institutes, so that it is characterized as a bureaucratic and hierarchical organization, where entrepreneurship becomes a challenge for its professoriate, researchers and managers. The methodological path of this research consisted in a phenomenological study and in a field research with a qualitative approach in which the subject discussion and the way of development are new and original, counting with a systematic review by Cochrane Handbook, realized on the Capes website. In the field research, the method of semi-structured face-toface interviews was adopted focusing on behavior. As to the information given by the interviewees, it were considered the statements which details of behavior were described. This information allowed the knowledge of the entrepreneurs skills exercised to leverage the ISEG Institution, that has remained one of the differentials of the UTL, and for the Portuguese society itself.
\end{abstract}

Keywords: Entrepreneurial skills. Entrepreneurship. Institution of Higher Education. 


\section{CONSIDERAÇÕES INICIAIS}

A moderna gestão, conduzida e suportada pelos gestores da organização, acrescenta novos elementos de reflexão de ação sistemática e continuada, permitindo que aqueles avaliem situações, elaborem projetos de mudança estratégica e acompanhem e gerenciem os passos de sua implantação (COSTA, 2007). Aí se inserem as Instituições de Educação Superior (IES), na busca permanente por conhecimento a fim de atender aos anseios da comunidade interna e da sociedade.

Um dos melhores métodos para que a inovação aconteça dentro das organizações, citado no trabalho de Russo e Sbragia (2007), é encorajar a busca pelo empreendedorismo. Por meio do empreendedorismo, a organização garante sua sobrevivência através da inovação dos processos, uma vez que desenvolve competências e habilidades criativas e inovações individuais e organizacionais (ALMEIDA, 2003).

Uma situação evolutiva instável e dinâmica, provocada pela globalização, tem-se colocado como desafio à gestão das IES. Identificar competências empreendedoras nessas instituições de ensino abre caminhos e possibilidades para a inclusão de uma categoria de indivíduos motivados a correr riscos, vislumbrar oportunidades e possibilitar a competitividade destas no mercado. Esse cenário traz à tona a figura do empreendedor como elemento humano capaz de criar e inovar. O fator humano é tido como principal combustível para a competitividade e inovação nas organizações, uma vez que o uso das tecnologias, isoladamente, não consegue assegurar benefícios para as organizações, sendo necessário o compartilhamento do conteúdo e da experiência, em clima profícuo à confiança e transparência entre os indivíduos que as compõem (CAVALCANTE; GOMES; PEREIRA NETO, 2001; FIGUEIREDO, 2004; MERLO, 2005).

Esse trabalhador diferenciado é alguém que incorporou ao seu modelo mental e às suas atividades uma postura a favor da instituição e de seu desenvolvimento científico e tecnológico. É aquele também que, tendo em vista a complexidade do mundo em que vive, sabe que ninguém mais detém sozinho o conhecimento necessário para que as coisas aconteçam. Portanto, sua autoimagem não é a de "mais uma peça na engrenagem", ou um "recurso humano", como acontecia na era industrial, mas sim a de alguém que faz a diferença (SALDANHA, 2005). Nesse sentido, Santos (2008) coloca a necessidade de um ambiente que promova a inovação na forma de empreendedores orientados para a construção da sociedade 
do conhecimento, caracterizada pelo padrão de desenvolvimento sustentável econômico, social, ambiental e tecnológico.

O modelo de gestão das IES, diferenciadas das demais instituições públicas por causa do seu grau de complexidade e papel diante da sociedade, precisa de gestores preparados e conhecedores do ambiente, para que os objetivos da instituição não sejam asfixiados em meio aos vários interesses e atividades existentes. $\mathrm{O}$ gestor precisa agir no sentido de quebrar resistências e convencer as pessoas da importância de contribuir para a causa comum (CUNHA, 2003; SCHWARTZMAN, 2006).

As IES são formadas por pessoas, processos e tecnologias, que executam atividades múltiplas, com uma metodologia de trabalho singular, o que as leva a serem conhecidas como organizações complexas e intensivas em conhecimento (LEITÃO, 1985; PEREIRA, 1999; RIZZATTI; RIZZATTI JÚNIOR, 2004). O processo de pensar e renovar essas organizações passa por uma mentalidade renovada pela visão empreendedora. As instituições universitárias são instrumento central da sociedade e da economia modernas e, conforme Santos (2008), atuam como catalisadoras dos demais setores da sociedade, representando uma parcela significativa dos investimentos em processos, desenvolvimento e inovação.

Portanto, as IES são consideradas organizações complexas por sua condição de instituição especializada, na qual cada tarefa tem uma metodologia de trabalho que lhe é própria, diferentemente daquela desenvolvida por outras organizações. Têm como matériaprima o conhecimento e existem para servir à sociedade e contribuir para o seu desenvolvimento, objetivando a formação de profissionais qualificados (CANDOTTI, 1993). Assim, podemos considerá-las instituições necessárias que têm como missão os caminhos do desenvolvimento do país.

Em decorrência dos desafios gerados por suas características específicas e também pelas transformações de um mundo globalizado e uma nova era no desenvolvimento da humanidade, chega-se à pergunta de pesquisa: "Quais são as competências empreendedoras existentes na Universidade Técnica de Lisboa que têm alavancado seu crescimento e sucesso?".

Para obter resposta a essa questão, estabeleceu-se um caminho metodológico a fim de elaborar o conjunto de competências empreendedoras encontradas entre os entrevistados da UTL. Para tal, fez-se necessário identificar as pessoas empreendedoras dessa instituição por 
meio de uma enquete inicial, com base em princípios do método Delphi, para então conhecer o perfil dos empreendedores entrevistados na investigação pela análise de conteúdo.

\section{PROCEDIMENTOS METODOLÓGICOS}

Para o caminho metodológico desta investigação adotou-se a pesquisa de campo, com abordagem qualitativa, em que a discussão do assunto e a forma do desenvolvimento são novas e originais, contando com revisão sistemática orientada pelo Cochrane Handbook, realizada no Portal da Capes.

Na pesquisa de campo, adotou-se o método de entrevistas presenciais semiestruturadas com foco em comportamento. Já foi observado por Spencer e Spencer (1993) que entrevistas tradicionais não funcionam bem para identificar competências; por isso, a finalidade do método foi tratar de encontrar, por trás do que as pessoas falaram, o que realmente elas fizeram. A partir dos dados obtidos, desenvolveu-se a análise de conteúdo com a categorização dos dados para proceder à construção de um conjunto de competências empreendedoras.

A população da pesquisa compreendeu a administração hierarquicamente superior do ISEG/UTL. A amostra foi definida pela enquete inicial, quando utilizaram-se princípios do método Delphi (GIOVINAZZO; FISCHMANN, 2002).

Durante a realização das entrevistas (FLANAGAN, 1973) foi utilizado o método da entrevista com foco em eventos comportamentais, observando-se os incidentes críticos descritos nas falas. A conversação foi conduzida em torno do foco da pesquisa, permitindo que o entrevistado falasse livremente, à medida que iam sendo feitas inferências na condução da entrevista.

Para a análise dos dados, utilizou-se a técnica de análise de conteúdo, com a classificação dos elementos contidos nas mensagens (FRANCO, 2008). Utilizou-se a análise categorial, que, segundo Bardin (2009, p. 199) "funciona por operações de desmembramento do texto em unidades". Para tal, os dados foram agrupados em unidades que permitiram descrição das características relevantes do conteúdo, ou seja, as categorias de análise (FRANCO, 2008). Nesse processo de categorização, segundo Bardin (2009, p. 199), a “análise tematica é rapida e eficaz na condição de se aplicar significações manifestas”. Assim, a análise de conteúdo iniciou com uma leitura global sobre o material, resultante das transcrições das entrevistas, passando em seguida por um recorte em suas partes, para serem 
categorizadas e classificadas. Esse processo permitiu a definição das categorias de análise, levando-se em consideração a dimensão empreendedora com os aspectos comportamentais, atitudes e habilidades.

\section{APRESENTAÇÃO E DISCUSSÃO DOS RESULTADOS DA INVESTIGAÇÃO}

Obteve-se um total de dezenove entrevistas com os empreendedores indicados no ISEG/UTL e ficou acordado o anonimato dos entrevistados. Dos dezenove entrevistados, doze eram homens e sete, mulheres; dezessete eram docentes e dois eram pesquisadores, todos com doutorado. Destes, cinco não apresentaram perfil empreendedor.

As entrevistas foram realizadas com foco nas ações dos entrevistados; no entanto, nem sempre os respondentes expressavam-se de forma pessoal. Nesses casos, a pesquisadora procurava refazer a pergunta de forma a levar o entrevistado a expressar-se de forma mais pessoal e coerente com sua visão da realidade. O motivo para isso é que os empreendedores percebem e distinguem o que os rodeia por seu conhecimento, que é "influenciado pelo ambiente ao qual o indivíduo faz parte, pela estrutura psicológica, social, política, ambiental, processos fisiológicos, necessidades e experiências anteriores (FIALHO et al., 2006). No entanto, alguns entrevistados $(5,8,11,12$ e 16), no momento da análise de conteúdo, não apresentaram competências empreendedoras por terem tido suas falas colocadas de forma que impossibilitou observar o que realmente estes fizeram, ou seja, essa forma de colocação não permitiu a observação de ações concretas dos empreendedores entrevistados.

Dornelas (2005) coloca que os empreendedores podem ser considerados produtos da época e do lugar em que vivem. Aspectos culturais, fatores temporais e lugar são variáveis que impactam diretamente nas iniciativas empreendedoras. Ainda Pinchot III (1989, p. 29) afirma que ser um empreendedor interno é um estado de espírito. Portanto, o conjunto de competências empreendedoras encontradas nessa parcela de empreendedores do ISEG/UTL reflete as ações dos empreendedores que obtiveram sucesso e satisfação pessoal em atividades desenvolvidas durante sua carreira profissional na Instituição.

Para definir as competências empreendedoras desta pesquisa, classificaram-se as categorias de análise como segue:

a) Comportamento empreendedor, em que se encontra o saber;

b) Habilidades empreendedoras, em que se encontra o saber fazer;

c) Atitudes, em que se encontra o querer fazer. 
Assim, o conjunto de competências empreendedoras encontradas no ISEG/UTL estão identificadas nos quadros apresentados a seguir.

O quadro 1 apresenta a primeira categoria de análise das competências empreendedoras, composta pelo comportamento de realização, a habilidade de condução de situação e as atitudes de ter persistência, buscar oportunidade e correr risco.

\begin{tabular}{|c|c|c|c|}
\hline Comportamento & Habilidade & Atitude & Entrevista no $^{0}$ \\
\hline Realizar & $\begin{array}{l}\text { Conduzir } \\
\text { situações }\end{array}$ & $\begin{array}{c}\text { Ter persistência } \\
\text { Buscar oportunidade } \\
\text { Correr risco }\end{array}$ & $\begin{array}{l}01 \text { e } 03 \\
07 \\
07 \text { e } 09\end{array}$ \\
\hline
\end{tabular}

Quadro 1 Primeira categoria de análise das competências empreendedoras encontradas na UTL

Fonte: Elaborado pelas autoras.

Lezana e Tonelli (1998, p. 15) afirmam que o empreendedor apresenta um "conjunto de características psicológicas relativamente estáveis que influenciam a maneira pela qual o indivíduo interage com seu ambiente.". O empreendedor busca a flexibilidade para a implementação de suas ideias e criações, já que é visto como aquele que desenvolve projetos que dão resultados (FILION, 2009). O empreendedor visto por McClelland (1969, p. 65) é "aquele cuja característica mais distintiva era a motivação para a realização". Almeida (2003, p. 63) conceitua o empreendedorismo como um "processo dinâmico em que o indivíduo identifica sistematicamente oportunidades". Os empreendedores são "pessoas que imaginam, desenvolvem e realizam visões" (FILION, 2004, p. 65). Em 1970, Peter Druker introduziu o conceito de risco à pessoa do empreendedor. McClelland (1961) argumenta que o empreendedor é aquele indivíduo com grande necessidade de realização e tolerância a riscos. Os empreendedores são criativos o suficiente para superar dificuldades e resolver problemas, e estão preparados para os novos e surpreendentes desafios. Eles têm necessidade de realização e traços distintos (FILION, 2009).

O quadro 2 apresenta a segunda categoria de análise das competências empreendedoras, composta pelo comportamento de realização, a habilidade de disposição para o trabalho e a atitude de orientar-se para resultados.

\begin{tabular}{|c|c|c|c|}
\hline Comportamento & Habilidade & Atitude & Entrevista n $^{\mathbf{0}}$ \\
\hline Realizar & Disposição para o trabalho & Orientar-se para resultados & 13 \\
\hline
\end{tabular}

Quadro 2 Segunda categoria de análise das competências empreendedoras encontradas na UTL

Fonte: Elaborado pelas autoras. 
Silva (1991) afirma que o empreendedor tem o comprometimento ou a responsabilidade pessoal pelo desempenho necessário para atingir metas e objetivos, além de ter grande disposição em colaborar com a finalização de um trabalho.

O quadro 3 apresenta a terceira categoria de análise das competências empreendedoras, composta pelo comportamento de realização, a habilidade de identificar oportunidades e as atitudes de ter iniciativa, inovar e ter visão.

\begin{tabular}{|c|c|c|c|}
\hline Comportamento & Habilidade & Atitude & Entrevista n $^{\mathbf{0}}$ \\
\hline \multirow{3}{*}{ Realizar } & Identificar & Ter iniciativa & 02 \\
& oportunidades & Inovar & 14 \\
& & Ter visão & 17 \\
\hline
\end{tabular}

Quadro 3 Terceira categoria de análise das competências empreendedoras encontradas na UTL

Fonte: Elaborado pelas autoras.

Araújo et al. (2005) apresentam uma série de características do empreendedor de sucesso, entre as quais está a característica de serem otimistas e apaixonados pelo que fazem, sonhadores realistas que acabam por traduzir seus pensamentos em ações. Silva (1991) afirma que o empreendedor aproveita oportunidades fora do comum, por ter iniciativa.

Dolabela (1999, p. 72-73) apresenta um quadro de competências empreendedoras no qual aborda a questão da descoberta de oportunidades pelo empreendedor, por ter a capacidade de reconhecer o que é útil e dá resultados, e ainda por suas visões em saber obter informações para realizar ajustes contínuos. Segundo Drucker (1986), os empreendedores estão sempre buscando mudanças, reagem a elas e as exploram como uma oportunidade nem sempre vista pelos demais.

Filion (1999) afirma que os empreendedores são pessoas singulares, visionárias e apaixonadas pelo que fazem. No mesmo sentido, Birley e Muzyka (2001) definem o empreendedor como um visionário capaz de identificar oportunidades. Ainda Dornelas (2005) afirma que o empreendedor é um administrador com a vantagem de ser mais visionário, e Almeida (2003) diz que o empreendedor é aquele que visualiza inovação e é motivado. Finalmente, nas palavras de Costa e Almeida (2002, p. 176), “Os empreendedores, geralmente visualizam a empresa como o local onde suas capacidades podem ser utilizadas e aperfeiçoadas e, em consequência, obtêm a realização pessoal.”. 
O quadro 4 apresenta a quarta categoria de análise das competências empreendedoras, composta pelo comportamento de planejar, a habilidade de liderança e a atitude de tomar decisão.

\begin{tabular}{|c|c|c|c|}
\hline Comportamento & Habilidade & Atitude & Entrevista n $^{\mathbf{0}}$ \\
\hline Planejar & Liderança & Tomar decisão & 18 \\
\hline
\end{tabular}

Quadro 4 Quarta categoria de análise das competências empreendedoras encontradas na UTL Fonte: Elaborado pelas autoras.

Dornelas (2005) afirma que os empreendedores, além de terem um senso de liderança incomum, não se sentem inseguros, pois principalmente nos momentos de adversidade sabem tomar decisões corretas e na hora certa.

O quadro 5 apresenta a quinta categoria de análise das competências empreendedoras, composta pelo comportamento de planejar, a habilidade de sentido de obrigação com os outros e as atitudes de ter espírito de equipe e gerir conflitos.

\begin{tabular}{|c|c|c|c|}
\hline Comportamento & Habilidade & Atitude & Entrevista $\mathbf{~ n}^{\mathbf{0}}$ \\
\hline \multirow{2}{*}{ Planejar } & Sentido de obrigação com & Ter espírito de equipe & 06 \\
& os outros & Gerir conflitos & 04 \\
\hline
\end{tabular}

Quadro 5 Quinta categoria de análise das competências empreendedoras encontradas na UTL Fonte: Elaborado pelas autoras.

Conforme Araújo et al. (2006), o empreendedor tem a capacidade de ser dedicado e com alto comprometimento. Agrega-se a esse conceito a afirmação de que o empreendedor é uma pessoa que sabe liderar e trabalhar em equipe (DOLABELA, 2004). Ainda Cunha (1997) coloca que o empreendedor agrega pessoas em torno de si no sentido de movê-las em direção ao objetivo pretendido. Nesse sentido, cita-se Silva (1991), ao observar que o empreendedor, ao comprometer-se, se esmera em manter os clientes satisfeitos e coloca em primeiro lugar a boa vontade.

Araújo et al. (2005) afirmam que os empreendedores são determinados, dinâmicos, perseverantes, planejam e sabem fixar metas e alcançá-las, além de procurarem feedbacks para se aprimorarem. Também Silva (2001) afirma que o empreendedor monitora sistematicamente e que constantemente revisa seus planos levando em conta os resultados obtidos e mudanças circunstanciais. Ainda Dornelas (2005) apresenta os empreendedores como grandes líderes formadores de equipes. 
O quadro 6 apresenta a sexta categoria de análise das competências empreendedoras, composta pelo comportamento de afiliação, a habilidade de rede de relacionamentos e as atitudes de buscar parcerias e compartilhar ideias.

\begin{tabular}{|c|c|c|c|}
\hline Comportamento & Habilidade & Atitude & Entrevista $\mathbf{~ n}^{\mathbf{0}}$ \\
\hline \multirow{2}{*}{ Afiliar } & $\begin{array}{c}\text { Rede de } \\
\text { relacionamentos }\end{array}$ & $\begin{array}{c}\text { Buscar parcerias } \\
\text { Compartilhar ideias }\end{array}$ & 03 \\
& $03 \mathrm{e} 09$ \\
\hline
\end{tabular}

Quadro 6 Sexta categoria de análise das competências empreendedoras encontradas na UTL Fonte: Elaborado pelas autoras.

Entre as características do empreendedor apresentadas por Araújo et al. (2005), encontra-se também a de formador de redes de contato, as quais ele utiliza de forma intensa a fim de alcançar seus objetivos. Dornelas (2005) diz que os empreendedores sabem construir uma rede de contatos que os auxiliam no ambiente externo da empresa.

McClelland (1973) identificou, em seu estudo sobre empresários de sucesso, outras duas necessidades dos empreendedores, que são as necessidades de poder e de afiliação. Silva (1991), ao trabalhar com características do comportamento empreendedor, afirma que este mobiliza estratégias deliberadas para influenciar suas redes de contato. Com isso, compartilha suas ideias, pois, segundo Dornelas (2005), o empreendedor é aquele que percebe uma oportunidade e cria meios para alcançá-la.

O quadro 7 apresenta a sétima categoria de análise das competências empreendedoras, composta pelo comportamento de poder, a habilidade de persuasão e a atitude de conseguir convencer.

\begin{tabular}{|c|c|c|c|}
\hline Comportamento & Habilidade & Atitude & ${\text { Entrevista } \mathbf{~}^{\mathbf{0}}}^{\text {Poder }}$ \\
\hline Persuasão & Conseguir convencer & 01 \\
\hline
\end{tabular}

Quadro 7 Sétima categoria de análise das competências empreendedoras encontradas na UTL

Fonte: Elaborado pelas autoras.

Segundo a visão psicológica com relação ao comportamento do empreendedor, Lezana e Tonelli (1998, p. 15), identificam um "conjunto de características psicológicas relativamente estáveis que influenciam a maneira pela qual o indivíduo interage com seu ambiente". Nesse sentido, o empreendedor é aquele que detém a capacidade de persuasão e consegue convencer, pois, segundo Silva (1991), utiliza estratégias deliberadas para conseguir convencer ou persuadir os outros. 
O quadro 8 apresenta a oitava categoria de análise das competências empreendedoras, composta pelo comportamento de poder, a habilidade de autoconfiança e as atitudes de prover recursos e ser independente.

\begin{tabular}{|c|c|c|c|}
\hline Comportamento & Habilidade & Atitude & Entrevista $^{0}{ }^{\circ}$ \\
\hline Poder & Autoconfiança & $\begin{array}{l}\text { Prover recursos } \\
\text { Ser independente }\end{array}$ & $\begin{array}{l}07 \\
10\end{array}$ \\
\hline
\end{tabular}

Quadro 8 Oitava categoria de análise das competências empreendedoras encontradas na UTL Fonte: Elaborado pelas autoras.

McClelland (1961), em sua teoria fundamentada na motivação psicológica e direcionada por necessidades básicas, coloca a necessidade de poder, caracterizada principalmente pela forte preocupação em exercer autoridade sobre os outros e, com isso, executar ações poderosas. Hisrich e Peters (2004, p. 29) explicam que "empreendedor é aquele que combina recursos, trabalho, materiais e outros ativos para tornar seu valor maior do que antes [...]. Para alguns homens de negócios um empreendedor aparece como [...] uma fonte de suprimento [...] alguém que cria riquezas [...]".

Birley e Westhead (1992) estudaram as necessidades mais comuns dos empreendedores e detectaram basicamente cinco tipos de necessidades: necessidade de aprovação, necessidade de independência, necessidade de desenvolvimento pessoal, necessidade de segurança e necessidade de autorrealização. Para Costa e Almeida (2002, p. 176), "Os empreendedores geralmente visualizam a empresa como o local onde suas capacidades podem ser utilizadas e aperfeiçoadas e, em consequência, obtêm a realização pessoal.”. Dornelas (2005) afirma que os empreendedores querem estar à frente das mudanças e querem ser independentes, pois querem criar algo novo e determinar os próprios passos.

O quadro 9 apresenta a nona categoria de análise das competências empreendedoras, composta pelo comportamento conhecer, a habilidade cognitiva e a atitude de perceber ideias.

\begin{tabular}{|c|c|c|c|}
\hline Comportamento & Habilidade & Atitude & Entrevista n $^{\mathbf{0}}$ \\
\hline Conhecer & Cognição & Perceber ideias & 09 \\
\hline
\end{tabular}

Quadro 9 Nona categoria de análise das competências empreendedoras encontradas na UTL Fonte: Elaborado pelas autoras.

Zarifian (1999) corrobora essa tese quando expõe que várias mutações estão acontecendo no mundo do trabalho. Dessa forma, não se pode mais entender o trabalho como um conjunto de tarefas que acabam por descrever o cargo, mas como um conjunto de recursos 
mobilizados pelo indivíduo, visto que o imprevisto cada vez se torna mais cotidiano e rotineiro. Conforme Dornelas (2005), os empreendedores sabem que quanto maior o domínio sobre um ramo de negócio, maior é sua chance de êxito. Daí a necessidade crescente da capacidade cognitiva, no sentido de trazer o novo e essencial para o crescimento e evolução da sociedade e, consequentemente, atender às necessidades das pessoas nela inseridas.

Spencer e Spencer (1993) classificam o conhecimento como um nível de competência que pode ser definido como a informação que a pessoa apresenta em nível satisfatório sobre uma área específica. Trata-se de uma competência complexa.

\begin{tabular}{|c|c|c|c|}
\hline Comportamento & Habilidade & Atitude & Entrevista $\mathbf{~}^{\mathbf{0}}$ \\
\hline \multirow{2}{*}{ Filantrópico } & \multirow{2}{*}{ Voluntário } & Doar-se & 15 \\
& & Ter empatia & 19 \\
\hline
\end{tabular}

Quadro 10 Décima categoria de análise das competências empreendedoras encontradas na UTL

Fonte: Elaborado pelas autoras.

O quadro 10 apresenta a décima categoria de análise das competências empreendedoras, composta pelo comportamento de filantropia, a habilidade de voluntariado e as atitudes: doar-se e ter empatia.

Carl Jung (1928), discípulo de Freud, ao tratar do perfil humano, apresenta quatro divisões ou dicotomias potencialmente presentes nos indivíduos. Estes podem ser introvertidos ou extrovertidos, sensitivos ou intuitivos, humanos ou científicos e julgadores ou perceptivos (MORALES, 2004; URIART, 2000; VÉRAS, 1999). Essas potencialidades estão presentes nos empreendedores, em uns de forma mais intensa e, em outros, menos.

Lopes (1999, p. 78), em sua pesquisa, afirma que "o empreendedorismo é ao mesmo tempo um papel social e um processo que ocorre nos níveis social e individual”. Grabinsky (1997) afirma que o empreendedor reúne características como disciplina, liderança e capacidade para organizar, visto que não se rende, busca o que deseja, possui pressentimento e intuição.

A definição operacional das categorias de análise acima descritas teve por finalidade identificar os aspectos observáveis na comunicação dos entrevistados, evidenciados pelos elementos comportamentais expressos verbalmente, o que permitiu organizar e descobrir elementos manifestos na realidade que os entrevistados comunicaram. Assim, a técnica de análise de conteúdo proporcionou o alcance dos resultados apresentados nesta pesquisa empírica, conforme o Quadro 11. 


\begin{tabular}{|c|c|c|}
\hline Comportamentos & Habilidades & Atitudes \\
\hline \multirow{10}{*}{ Realizar } & \multirow{3}{*}{ Conduzir situações } & Buscar oportunidades \\
\hline & & Ter persistência \\
\hline & & Correr riscos calculados \\
\hline & \multirow{5}{*}{ Identificar oportunidades } & Ter visão \\
\hline & & Ter iniciativa \\
\hline & & Ter sonhos \\
\hline & & Ter determinação \\
\hline & & Inovar \\
\hline & \multirow{2}{*}{ Ter disposição para o trabalho } & Ter foco em resultados \\
\hline & & Buscar desafios \\
\hline \multirow{7}{*}{ Planejar } & \multirow{3}{*}{ Ter liderança } & Tomar decisões \\
\hline & & Buscar informações \\
\hline & & Ter dedicação \\
\hline & Prever situação & Enxergar tendências \\
\hline & \multirow{3}{*}{ Ter sentido de obrigação com os outros } & Ter espírito de equipe \\
\hline & & Assumir responsabilidade \\
\hline & & Gerir conflitos \\
\hline \multirow{4}{*}{ Afiliar } & \multirow{4}{*}{ Constituir rede de relacionamentos } & Compartilhar ideias \\
\hline & & Criar valor \\
\hline & & Saber negociar \\
\hline & & Buscar parcerias \\
\hline \multirow{4}{*}{ Poder } & Conduzir situação & Correr risco \\
\hline & Ter persuasão & Conseguir convencer \\
\hline & \multirow{2}{*}{ Ter autoconfiança } & Ser independente \\
\hline & & Prover recursos \\
\hline \multirow{3}{*}{ Conhecer } & \multirow{3}{*}{ Ter cognição } & Perceber ideias \\
\hline & & Adquirir conhecimento \\
\hline & & Dominar processo \\
\hline Ser filantrópico & Ser voluntário & Ter empatia \\
\hline
\end{tabular}

Quadro 11 Conjunto de competências empreendedoras encontradas na UTL

Fonte: Elaborado pelas autoras.

\section{CONSIDERAÇÕES FINAIS}

No campo da competência empreendedora em instituições universitárias, há ainda muito a ser explorado, visto que esta investigação encontra-se em fase muito inicial e circunscrita. No entanto, a participação dos vários entrevistados envolvidos no ensino, na investigação e na gestão, cada um com suas especificidades, contribuiu para a produção deste saber específico, que envolveu as mais diferentes atitudes e conhecimentos individuais na solução dos vários desafios que se apresentaram durante seu percurso profissional. Essas ações deram respostas mais amplas e variadas aos problemas enfrentados, surgidos durante esta investigação, por meio das entrevistas. 
Exploraram-se, por meio dos estímulos às respostas, o objetivo que era encontrar, por trás do que era dito, o que realmente era feito. Assim, as respostas obtidas foram afirmações sobre pensamentos, sentimentos e atitudes dos entrevistados quanto a diversas ações empreendidas, corroborando com o foco da entrevista comportamental. Consideraram-se nas informações explanadas pelos entrevistados as afirmações nas quais eram descritos os detalhes do comportamento. Foram essas informações que permitiram o conhecimento das competências empreendedoras que dão continuidade e que alavancam o Instituto ISEG, que tem se mantido como um dos diferenciais da UTL.

Embora os sujeitos entrevistados apresentassem diferenças em suas colocações, que são particulares e influenciadas por sua personalidade, ambiente e localização geográfica, social e histórica, esta pesquisa deixou claro que o sentimento que paira na cabeça dos empreendedores está intimamente relacionado ao compromisso com a instituição, com a sociedade, com a nação e com seus interesses pessoais.

O recorte diferenciado desta investigação possibilita aos gestores deste Instituto conhecer as competências empreendedoras que promovam resultados inovadores, transcendendo paradigmas, além de identificar obstáculos que dificultam e até emperram as atividades práticas, impulsionando à postura criativa, responsável, ética e humana. Por fim, obteve-se o conjunto de competências empreendedoras que possibilitaram a resolução de problemas e o crescimento institucional, bem como as habilidades, conhecimentos e atitudes que têm permeado a compreensão do processo ensino-aprendizagem-gestão-investigação desse local tão importante da sociedade portuguesa.

Assim espera-se que o conjunto de competências empreendedoras apresentadas pelos atores organizacionais contribua para a velocidade e inovação dos processos e produtos dessa IES, implicando na evolução de aportes para o desenvolvimento científico e tecnológico não só pessoais, mas institucionais e de toda a sociedade portuguesa.

\section{REFERÊNCIAS}

ALMEIDA, Pedro J. M. B. de. Da capacidade empreendedora aos ativos intangíveis no processo de criação de empresas do conhecimento. Dissertação (Mestrado em Engenharia e Gestão da Tecnologia) - Universidade Técnica de Lisboa, Instituto Superior Técnico. Lisboa, 2003. $179 \mathrm{f}$.

ARAÚJO, P. C. et al. Empreendedorismo e educação empreendedora: confrontação entre a teoria e prática. Revista de Ciências da Administração, Florianópolis, v. 8, n. 15, p. 9-29, jan/jun 2006. 
ARAÚJO, Maria H. et al. O estímulo ao empreendedorismo nos cursos de química: formando químicos empreendedores. Revista Química Nova, v. 28, p. 518-525, dez. 2005.

BARDIN, Laurence. Análise de conteúdo. 4. ed. Lisboa: Edições 70, 2009. 281 p.

BIRLEY, Sue; MUZYKA, Daniel K. Dominando os desafios do empreendedor. São Paulo: Makron Books, 2001. 356 p.

BIRLEY, S.; WESTHEAD, P. A comparison of new firms in "assisted" and "non" assisted areas in Great Britain. Entrepreneurship and Regional Development, London, v. 4, n. 4, p. 299-238, 1992.

CAIRD, S. Testing enterprising tendency of occupational groups. British Journal of Management, v. 2, p. 177-183, 1991.

CANDOTTI, E. Universidade e cultura rumo ao ano 2000: projeto político nacional. Educação Brasileira, Brasília, v. 15, n. 30, 1993.

CAVAlCANTE, M. C. B.; GOMES, E. B. P.; PEREIRA NETO, A. F. Gestão de empresas na sociedade do conhecimento: um roteiro para a ação. Rio de Janeiro: Campus, 2001. 170p.

COSTA, Benny K.; ALMEIDA, Martinho I. R. de. Estratégia: perspectivas e aplicações. São Paulo: Atlas, 2002. 344 p.

Eliezer A. da. Gestão estratégica: da empresa que temos para a empresa que queremos. 2. ed. São Paulo: Saraiva, 2007. 424 p.

CUNHA, Cristiano J. C. A. Iniciando o seu próprio negócio. Florianópolis: Instituto de Estudos Avançados/UFSC, 1997.

, Luiz A. O ensino superior no octênio FHC. Revista Educação \& Sociedade, São Paulo, v. 24, n. 82, p. 37-61, abr. 2003.

DOLABELA, F. O segredo de Luísa. São Paulo: Cultura Editores Associados, 1999. 304 p. abr./jun. 2004.

F. Pedagogia empreendedora. Revista de Negócios, Blumenau, v. 9, n. 2, p.127-130,

DORNELAS, José C. A. Empreendedorismo: transformando idéias em negócios. 2. ed. Rio de Janeiro: Campus, 2005. 293 p.

DRUKER, Peter. Technology, management and society. New York: Harper and Row, 1970. $224 \mathrm{p}$.

, Peter. The frontiers of management. New York: Plume, 1986. 384 p.

FIALHO, Francisco A. P. et al. Gestão do conhecimento e aprendizagem. Florianópolis: Visual Books, 2006. 196 p. 
FIGUEIREDO, Saulo P. Gestão do conhecimento: estratégias competitivas para a criação e mobilização do conhecimento na empresa. Rio de Janeiro: QualityMark, 2004. 379 p.

FILION, L. J. Empreendedorismo: empreendedores e proprietários - gerentes de pequenos negócios. Revista de Administração da USP, São Paulo, v. 34, n. 2, p. 5-28, 1999.

, Louis J. Entendendo os intraempreendedores como visionistas. Revista de Negócios, Blumenau, v. 9, n. 2, p. 65-80, abr./jun. 2004.

, Louis J. Intraempreendedorismo na era do conhecimento. In: ENEMPRE -

ENCONTRO NACIONAL DE EMPREENDEDORISMO, 6., 2009, Lages. Anais... Lages:

EGC/UFSC, 2009. Disponível em: <http://www.congressos.egc.ufsc.br/enempre2009/>.

Acesso em: 15 abr. 2010.

FLANAGAN, J. C. A técnica do incidente crítico. Arquivos Brasileiros de Psicologia Aplicada, Rio de Janeiro, v. 25, n. 2, p. 99-141, abr./jun.1973.

FRANCO, Maria Laura P. B. Análise de conteúdo. 3 ed. Brasília: Liber Livro, 2008, 79 p.

GIOVINAZZO, R. A.; FISCHMANN, A. A. Delphi eletrônico: uma experiência de utilização da metodologia de pesquisa e seu potencial de abrangência regional. In: COSTA, B. K.;

ALMEIDA, M. I. R. Estratégias: perspectivas e aplicações. São Paulo: Atlas, 2002. 344 p.

GRABINSKY, S. El emprendedor. México: Del Verbo Emprender, 1997. 267 p.

HASHIMOTO, M. Espírito empreendedor nas organizações: aumentando a competitividade através do intraempreendedorismo. São Paulo: Saraiva, 2006. 277 p.

HISRICH, Robert D.; PETERS, Michael P. Empreendedorismo. Tradução de Lene Belon Ribeiro. 5. ed. Porto Alegre: Bookman, 2004, 592 p.

JUNG, Carl G. Psychological types. London: Rotledge \& Kegan Paul, 1928. 625 p.

LEITÃO, Sérgio P. A questão organizacional na universidade: as contribuições de Etizione e Rice. Revista de Administração Pública, Rio de Janeiro, v. 19, n. 4, p. 3-26, out./dez. 1985.

LEZANA, A. G. R.; TONELLI, A. O comportamento do empreendedor. In: DE MORI, F. (Org.). Empreender: identificando, avaliando e planejando um novo negócio. Florianópolis: ENE/UFSC, 1998. 96 p.

LOPES, Rose M. A. Avaliação de resultados de um programa de treinamento comportamental para empreendedores EMPRETEC. Dissertação (Mestrado em Psicologia) Universidade de São Paulo. São Paulo, 1999. 304 f.

LUCHSINGER, V.; BAGBY, D. R. Entrepreneurship and intrapreneurship: behaviors, comparisons, and contrasts. S.A.M. Advanced Management Journal, v. 52, n. 3, p. 10-13, Summer 1987. 
LUMPKIN, G. T.; DESS, G. G. Clarifying the entrepreneurial orientation construct and linking it to performance. The Academy of Management Review, v. 21, n. 1, p. 135-172, jan. 1996.

MCCLELLAND, David C. The achieving society. New York: D. Van Nostrand, 1961. 512p.

, David C.; WINTER, D. G. Motivating economic achievement: accelerating economic development through psychological training. New York: The free Press, 1969.

, D. Testing for competence rather than for intelligence. American Psychologist, Washington, v. 28, n. 1, p. 1-4, jan. 1973.

MERLO, Tereza R. O paradigma da gestão de conhecimento: uma questão de enquadramento à cultura organizacional. Disponível em: $<\mathrm{http}: / / \mathrm{www} . \mathrm{kmol}$.online.pt/artigos/index.html $>$. Acesso em: 27 abr. 2005.

MORALES, Sandro A. Relação entre competências e tipos psicológicos junguianos nos empreendedores. Tese (Doutorado em Engenharia de Produção) - Universidade Federal de Santa Catarina. Florianópolis, 2004. 199 f.

PEREIRA, Fernanda C. B. Administração estratégica nas universidades federais: um estudo de caso na Universidade Federal de Santa Catarina. Dissertação (Mestrado em Engenharia de Produção) - Universidade Federal de Santa Catarina. Florianópolis, 1999. 159f.

PINCHOT III, Gifford. Intraempreendedorismo: por que você não precisa deixar a empresa para tornar-se um empreendedor. São Paulo: Harbra, 1989. 312 p.

RIZZATTI, Gerson; RIZZATTI JÚNIOR, Gerson. Organização universitária: mudanças na administração e nas funções administrativas. In: IV COLÓQUIO INTERNACIONAL DE GESTÃO UNIVERSITÁRIA NA AMÉRICA DO SUL. 2004, Florianópolis. Alianças estratégicas, integração e gestão universitária. Anais... Florianópolis: INPEAU/UFSC, 2004. CD ROOM - ISBN 987-544-025-6.

RUSSO, Rosália F. S. M.; SBRAGIA, Roberto. Tendência empreendedora do gerente: uma análise de sua relevância para o sucesso de projetos inovadores. Gestão \& Produção, São Carlos, v. 14, n. 3, p. 581-593, set./dez. 2007.

SANTOS, Neri dos. Parques científicos e tecnológicos como fator de desenvolvimento econômico e social. Instituto de Pesquisas e Estudos em Administração Universitária INPEAU/CSE/UFSC: Fórum Universidade em Debate. Florianópolis, 20 de agosto de 2008. Relatório. Mimeografado.

SALDANHA, Ricardo. Para compreender o "trabalhador do conhecimento". Disponível em: <http://www.kmol.online.pt/artigos/index.html>. Acesso em: 27 abr. 2005.

SCHUMPETER, Joseph A. The theory of economic development. Cambridge, Massachusetts: Harvard University Press, 1934. 267 p. 
SCHWARTZMAN, Simon. O ensino superior no Brasil. Disponível em:

$<$ http://www.inep.gov.br/download/cibec/1998/textos_para_discuss $\%$ C3\%A3o/miolo_textos Discus\%C3\%A3o_Superior_Brasil.pdf.>. Acesso em: 6 ago. 2006.

SILVA, Zita G. da. O perfil psicológico do empreendedor. Belo Horizonte: Manual do Modelo CEFE - GTZ/LUSO CONSULT/CENTRO CAPE, 1991. Mimeografado.

SPENCER, Lyle M.; SPENCER, Signe M. Competency at work: models for superior performance. New York: John Wiley \& Sons, 1993. 372 p.

URIART, Luiz R. Identificação do perfil intraempreendedor. Dissertação (Mestrado em Engenharia de Produção) - Universidade Federal de Santa Catarina. Florianópolis, 2000. $139 f$.

VÉRAS, Gabriela. Como ser empresário. Revista Jovem Empreendedor, p. 12-16, 1999.

ZARIFIAN, Philippe. Objectifs compétences: pour une nouvelle logique. Paris: Editions Liaisons, 1999. $232 \mathrm{p}$. 